Article

\title{
Shipborne Acquisition, Tracking, and Pointing Experimental Verifications towards Satellite-to-Sea Laser Communication
}

\author{
Dong $\mathrm{He}^{1,2,3}$, Qiang Wang ${ }^{1,2}$, Xiang Liu ${ }^{1,2}$, Zhijun Song ${ }^{1,2}$, Jianwei Zhou ${ }^{1,2}$, Zhongke Wang ${ }^{1,2}$, \\ Chunyang Gao ${ }^{1,2}$, Tong Zhang ${ }^{1,2}$, Xiaoping $\mathrm{Qi}^{1,2}{ }^{1,}, \operatorname{Tan}^{1,2}$, Ge Ren ${ }^{1,2}$, Bo Qi ${ }^{1,2}$, Jigang Ren ${ }^{4,5}$, \\ Yuan $\mathrm{Cao}^{4,5}$ and Yongmei Huang ${ }^{1,2,3, *}$
}

1 Institute of Optics and Electronics, Chinese Academy of Sciences, No.1 Guangdian Road, Chengdu 610209, China; hedong@ioe.ac.cn (D.H.); wangqiang19750731@126.com (Q.W.); lx061990@163.com (X.L.); lala_xy@163.com (Z.S.); zjw96312@163.com (J.Z.); 15902875845@163.com (Z.W.); 13880872834@163.com (C.G.); 13880609238@163.com (T.Z.); 1qixiaoping@163.com (X.Q.); tandeman@126.com (Y.T.); renge@ioe.ac.cn (G.R.); qibo@ioe.ac.cn (B.Q.)

2 Key Laboratory of Optical Engineering, Chinese Academy of Sciences, Chengdu 610209, China

3 University of Chinese Academy of Sciences, Beijing 100049, China

4 Department of Modern Physics and Hefei National Laboratory for Physical Sciences at the Microscale, University of Science and Technology of China, Hefei 230026, China; jgren@ustc.edu.cn (J.R.); yuancao@ustc.edu.cn (Y.C.)

5 Chinese Academy of Sciences (CAS) Center for Excellence and Synergetic Innovation Center in Quantum Information and Quantum Physics, University of Science and Technology of China, Shanghai 201315, China

* Correspondence: huangym@ioe.ac.cn

Received: 1 August 2019; Accepted: 16 September 2019; Published: 19 September 2019

check for updates

\begin{abstract}
Acquisition, tracking, and pointing (ATP) is a key technology in free space laser communication that has a characteristically high precision. In this paper, we report the acquisition and tracking of low-Earth-orbit satellites using shipborne ATP and verify the feasibility of establishing optical links between laser communication satellites and ships in the future. In particular, we developed a shipborne ATP system for satellite-to-sea applications in laser communications. We also designed an acquisition strategy for satellite-to-sea laser communication. In addition, a method was proposed for improving shipborne ATP pointing error. We tracked some stars at sea, achieving a pointing accuracy of less than $180 \mu \mathrm{rad}$.We then acquired and tracked some low-Earth-orbit satellites at sea, achieving a tracking accuracy of about $20 \mu \mathrm{rad}$. The results achieved in this work experimentally demonstrate the feasibility of ATP in satellite-to-sea laser communications.
\end{abstract}

Keywords: satellite-to-sea laser communication; acquisition, tracking and pointing; shipborne ATP; pointing error model

\section{Introduction}

Laser communication is a technology that uses a laser beam as a carrier to transmit information in space [1,2]. The laser beam used in space laser communication is emitted at an angle that is near the diffraction limit. The divergence angle of very narrow communication beams requires both communicating sides to maintain extremely high dynamic alignment accuracy. With the ultimate aim of realizing a global-scale laser communication for practical use, many significant achievements have been made in the past decades, such as the demonstration of links for building-to-building communication [3,4], airborne applications [5-7], inter-satellite applications [8,9], satellite-to-ground [10-16], and ship-to-ship communication [17-19]. However, currently, most of the 
experiments only involve space and ground communication links or short-distance communication between ships. Since water bodies occupy more than $70 \%$ of the earth's surface and given the rising demand for maritime communications, the global-scale communication network is bound to extend from the ground to the sea in the future. Huge volumes of data need to be transmitted by satellite. Thus, there is an urgent need to conduct experimental verifications of laser communication between satellites and ships at sea.

Satellite-to-sea laser communication mainly refers to data transmission between satellites and shipboards. Acquisition, tracking, and pointing (ATP) is the key technology used in laser communication, which requires the rapid acquisition and alignment of line-of-sight between two platforms and the establishment of communication links with high precision, high probability, and high dynamic tracking. The ATP system's rapid and high probability acquisition of a satellite terminal's line-of-sight under shipborne conditions has a direct impact on the communication time. Currently, optical links between ships have been verified. The link is usually initiated actively by an ATP at one end to cover an uncertain area with beacon light, then scanned or stared at by an ATP at another end to establish the link. This method of establishing an optical link is the most common method in laser communication, which requires high pointing accuracy. For short-distance communication links of tens of kilometers between ships or in air [20,21], the divergence angle and optical power of the beacon light can be improved, and the requirement of the ATP with respect to the pointing accuracy can be reduced to reduce the difficulty of acquisition. Another method for realizing short-range ship-to-ship laser communication is using modulating retro-reflectors (MRRs). An MRR link uses an active ATP at one end and a small semi-passive MRR at the other [22-25]. For one end of the link, MRRs no longer have tight pointing requirements. However, satellite-to-sea laser communication is very different from ground ATP systems. For ship-to-ship laser communications of tens of kilometers, the divergence angle of the uplink beacon is usually only a few milliradians due to resource constraints. The MMR method is less likely to achieve communication over hundreds or thousands of kilometers of links. Moreover, the complex nature of the ocean environment significantly increases the difficulty of acquisition and tracking by the ATP system. It is difficult for shipborne ATP systems to achieve high pointing accuracy to complete initial acquisition under conditions such as random and sharp waggling along with the sea, which poses a higher challenge to its technology. As a first step toward satellite-to-sea laser communication, it is essential to develop shipborne ATP and test its performance.

In this paper, we report the acquisition and tracking of low-Earth-orbit satellites using shipborne ATP and verify the establishment of optical links between laser communication satellites and a ship at sea. To improve the initial pointing accuracy of line-of-sight in the satellite-to-sea laser communication, we designed a calibration method for the shipborne ATP pointing error model. Some satellites were acquired and tracked by the ATP system, thereby demonstrating the acquisition and tracking performance of the ATP system at sea. A tracking accuracy of about $20 \mu$ rad was obtained, together with a pointing accuracy of less than $180 \mu \mathrm{rad}$.Our implementation provides a solid test for shipborne ATP, thus paving the way for a global-scale laser communication network involving space, ground, and sea.

\section{Strategies for Establishing Optical Links}

We designed an acquisition process for satellite-to-sea laser communication. The communication handshake is initiated by shipborne ATP. The terminals on each side of the communication drive their respective optical antennas to roughly align with each other's instantaneous positions according to the ephemeris and attitude information. Shipborne ATP has high-precision pointing ability and can transmit uplink beacon light to accurately cover the satellite terminal. After the satellite coarse Charge Coupled Device (CCD) detects the beacon light of the shipborne ATP, closed-loop tracking is carried out with high accuracy. The satellite terminal emits downlink beacon light. After the downlink beacon light is detected by the shipboard ATP coarse CCD, stable closed-loop tracking is conducted to complete the acquisition. After establishing a stable communication link between the satellite and 
the sea, laser communication is achieved until the satellite passes through. The acquisition strategy is summarized in Figure 1.

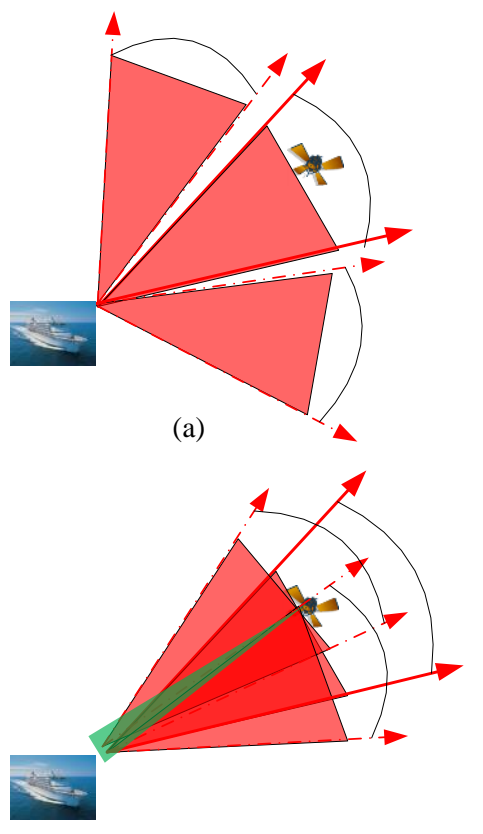

(c)

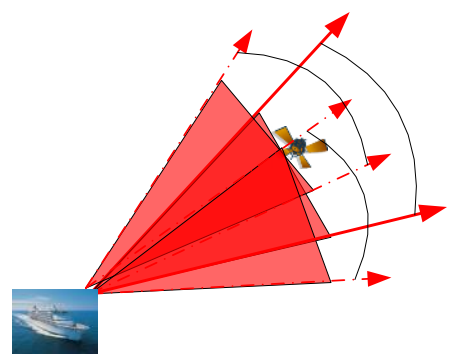

(b)

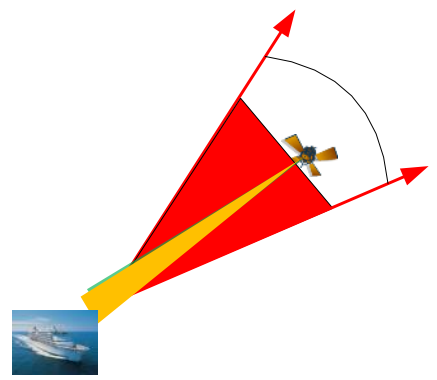

(d)

Figure 1. Schematic of acquisition and tracking. (a) The shipborne acquisition, tracking, and pointing (ATP) system initiates the acquisition process. The shipborne ATP and satellite activate their beacon lasers and point at each other using the predicted ephemeris. (b) The satellite detects the uplink beacon laser and initiates precise tracking. (c) The shipborne ATP detects the downlink beacon laser and initiates precise tracking. (d) Bidirectional tracking and locking between the satellite and shipborne ATP is established until the laser communication is terminated.

\section{Method for Improving the Pointing Error}

The acquisition protocol involves the shipborne ATP irradiating the satellite to initiate a link. The ATP is fixed on the ship. As the ship moves, the ATP is affected by sea waves, thus producing three periodic yaw, pitch, and roll disturbances, which cause the ATP's line-of-sight axis to wobble a few degrees. The divergence angle of the uplink beacon laser cannot be increased indefinitely; it is generally several milliradians and much smaller than the swaying amplitude. To achieve the acquisition of a satellite, the acquisition performance can only be improved by reducing the pointing error. The absolute pointing error is defined as the angular separation between the actual direction and the intended ATP line-of-sight [26]. In invisible satellite target acquisition, the pointing accuracy of the telescope is one of the important indices for the establishment of optical links. In our experiment, several factors contribute to the pointing error, including the attitude of the ship platform pre-compensation accuracy, installation error calibration accuracy, and systematic errors calibration accuracy.

\subsection{Pre-compensation for Ship Platform Attitude}

During the initial acquisition stage, the target coordinate value $(\mathrm{A}, \mathrm{E})$ in the Northeast celestial coordinate system is converted to $\left(\mathrm{A}_{\mathrm{c}^{\prime}} \mathrm{E}_{\mathrm{c}}\right)$ in the deck coordinate system. $\left(\mathrm{A}_{\mathrm{c}^{\prime}}, \mathrm{E}_{\mathrm{c}}\right)$ is used to guide the ATP to open-loop pointing.

As shown in Figure 2a, the Northeast celestial coordinate system is defined as O-XYZ, where OX is due North, $\mathrm{OY}$ is due east, and $\mathrm{OZ}$ is due sky. The origin, $\mathrm{O}$ is the intersection of the azimuth axis and the pitching axis of the tracking equipment. The polar coordinates of the observation point, $\mathrm{M}$ are (A, E), while the projection of $\mathrm{M}$ on the OXY plane is N. A represents the azimuth angle, that is, the included angle of $\mathrm{XON}$, which is positive when overlooking clockwise. E represents the elevation 
angle, which is the angle MON, where up is positive. L represents the distance from the tracking device to the observation point.

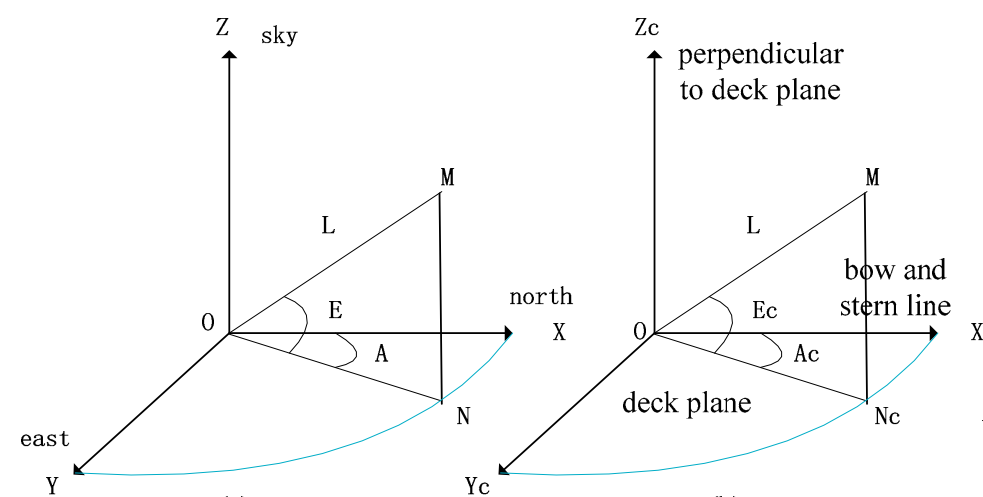

(a)

(b)

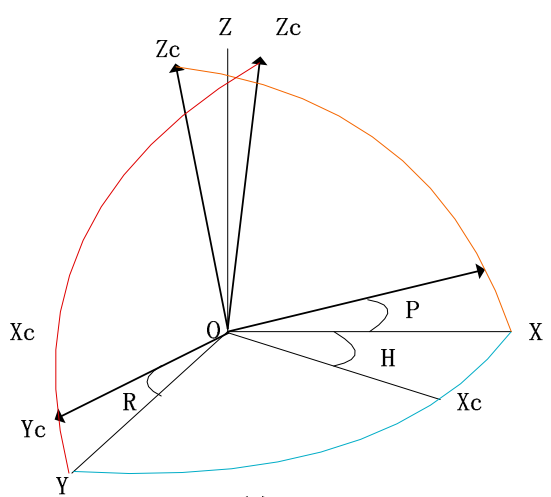

(c)

Figure 2. Schematic diagram of coordinate system and attitude angle. (a) The Northeast celestial coordinate system O-XYZ. (b) The deck coordinate system $\mathrm{O}-\mathrm{X}_{\mathrm{c}} \mathrm{Y}_{\mathrm{c}} \mathrm{Z}_{\mathrm{c}}$. (c) Definition of attitude angle.

As shown in Figure $2 b$, the deck coordinate system $O-X_{c} Y_{c} Z_{c}$ is defined; the axis $X_{c}$ is the fore-and-aft line, while the bow direction is forward. The axis $\mathrm{OZ}_{\mathrm{c}}$ is positive clock wise; the axis $\mathrm{Y}_{\mathrm{c}}$ is perpendicular to the fore-and-aft line in the deck plane, whereas the axis $\mathrm{OZ}_{\mathrm{c}}$ is perpendicular to the deck plane, upward is positive. The origin $\mathrm{O}$ is consistent with the Northeast celestial coordinate system. The projection point of $\mathrm{M}$ on plane $\mathrm{OX}_{c} \mathrm{Y}_{\mathrm{c}}$ is $\mathrm{N}_{\mathrm{c}}$. The polar coordinates of $\mathrm{M}$ in the deck coordinate system are defined as $\left(A_{c}, E_{c}\right)$. $A_{c}$ represents the azimuth angle of the deck, where clockwise is positive. $\mathrm{E}_{\mathrm{C}}$ represents the elevation angle of the deck; upward is positive.

As shown in Figure 2c, the roll angle, $\mathrm{R}$ is the angle obtained by rotating the fore-and-aft line of the deck platform, and the port side rising is defined as a positive angle. The pitch angle, $\mathrm{P}$ is the angle included between the fore-and-aft line and the horizontal plane, and $\mathrm{P}$ is the positive angle when the bow is raised. The yaw angle, $\mathrm{H}$ is the rotation angle of the fore-and-aft line about the $\mathrm{z}$-axis, and the clockwise angle is the positive angle.

When the shipborne ATP tracks a target, it is necessary to convert (A, E) of the target in the Northeast celestial coordinate system to $\left(\mathrm{A}_{\mathrm{c}}, \mathrm{E}_{\mathrm{c}}\right)$ of the deck coordinate system for guidance and tracking.

In the Northeast celestial coordinate system, the transformation relationship exists between the polar coordinate system and rectangular coordinate system is given by Equation (1):

$$
\left\{\begin{array}{l}
\mathrm{x}=L \cos E \cos \mathrm{A} \\
\mathrm{y}=L \cos E \sin \mathrm{A} \\
\mathrm{z}=L \sin \mathrm{E}
\end{array}\right.
$$

In the deck coordinate system, the transformation relationship between the polar coordinate system and rectangular coordinate system is given by Equation (2):

$$
\left\{\begin{array}{l}
\mathrm{x}_{\mathrm{c}}=L \cos \mathrm{E}_{\mathrm{c}} \cos \mathrm{A}_{\mathrm{c}} \\
\mathrm{y}_{\mathrm{c}}=L \cos \mathrm{E}_{\mathrm{c}} \sin \mathrm{A}_{\mathrm{c}} \\
\mathrm{z}_{\mathrm{c}}=L \sin \mathrm{E}_{\mathrm{c}}
\end{array}\right.
$$

When the ship is affected by yaw, pitch, and roll at the same time, it shall be convertedin the order of yaw, pitch, and roll. The attitude rotation matrix, $\xi t$ is given by Equation (3):

$$
\xi t=\left[\begin{array}{ccc}
1 & 0 & 0 \\
0 & \cos \mathrm{R} & \sin \mathrm{R} \\
0 & -\sin \mathrm{R} & \cos \mathrm{R}
\end{array}\right]\left[\begin{array}{ccc}
\cos \mathrm{P} & 0 & \sin \mathrm{P} \\
0 & 1 & 0 \\
-\sin \mathrm{P} & 0 & \cos \mathrm{P}
\end{array}\right]\left[\begin{array}{ccc}
\cos \mathrm{H} & \sin \mathrm{H} & 0 \\
-\sin \mathrm{H} & \cos \mathrm{H} & 0 \\
0 & 0 & 1
\end{array}\right]
$$


The conversion expression is shown in Equation (4) below:

$$
\begin{aligned}
{\left[\begin{array}{l}
x_{c} \\
y_{c} \\
z_{c}
\end{array}\right]=} & =\left[\begin{array}{l}
x \\
y \\
z
\end{array}\right] \\
= & {\left[\begin{array}{lll}
\cos H \cos P & \sin H \cos P & \sin P \\
-\sin H \cos R-\cos H \sin P \sin R & \cos H \cos R-\sin H \sin P \sin R & \cos P \sin R \\
-\cos H \sin P \cos R+\sin H \sin R & -\sin H \sin P \cos R-\cos H \sin R & \cos P \cos R
\end{array}\right]\left[\begin{array}{l}
x \\
y \\
z
\end{array}\right] }
\end{aligned}
$$

It can be obtained the Equation (5) from Equations (1) and (2):

$$
\left\{\begin{array}{l}
\mathrm{A}_{\mathrm{c}}=\operatorname{arctg}\left(\frac{\mathrm{y}_{\mathrm{c}}}{\mathrm{x}_{\mathrm{c}}}\right) \\
\mathrm{E}_{\mathrm{c}}=\arcsin \left(\frac{\mathrm{z}_{\mathrm{c}}}{\mathrm{L}}\right)
\end{array}\right.
$$

Thus, the target guidance value under the deck coordinate system can be obtained, as shown in Equation (6):

$$
\left\{\begin{array}{l}
A_{c}=\operatorname{arctg}\left\{\frac{\cos E[\cos R \sin (A-H)-\sin P \sin R \cos (A-H)]+\sin E \cos P \sin R}{\cos E \cos P \cos (A-H)+\sin E \sin P}\right\} \\
E_{C}=\arcsin \{\sin E \cos P \cos R-\cos E[\sin R \sin (A-H)+\sin P \cos R \cos (A-H)]\}
\end{array}\right.
$$

It can be seen from Equation (6) that the measurement accuracy for attitude (H, P, R) is one of the key factors affecting the accuracy of shipborne ATP pointing. The attitude error of the shipborne ATP is the main source of error that affects the orientation of the line-of-sight. We used an attitude pre-compensation unit (Figure 3), which used a combined inertial navigation equipment composed of a gyroscope, accelerometer, and GPS (GPS/INS) to measure the attitude of the ship. We made pre-compensation for the attitude by $200 \mathrm{~Hz}$, compensating for the wobble of the ATP line-of-sight axis caused by the swaying of the ship. The attitude error of the shipborne ATP is the main source of error that affects the orientation of the line-of-sight. The attitude of the ship is measured by the GPS/INS unit, which is converted into a compensation amount for the ATP line-of-sight axis for real-time attitude compensation using Equation (6).

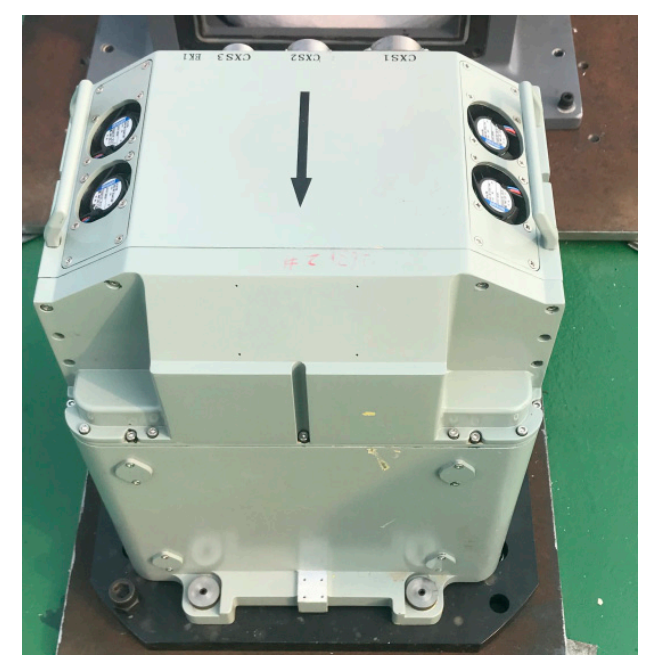

Figure 3. Attitude pre-compensation unit.

The accuracy of the GPS/INS unit measurement is shown in Table 1. The angle measurement error for the GPS/INS unit roll and pitch direction root-mean-square (RMS) was $\delta_{\text {Pitch }}=\delta_{\text {Roll }}=0.09 \mathrm{mrad}$ (root-mean-square.) whereas the yaw direction angle measurement error was $\delta_{\text {Yaw }}=0.18 \mathrm{mrad}$ (RMS). 
Table 1. GPS/INS unit attitude measurement accuracy.

\begin{tabular}{cc}
\hline Attitudeangle & Accuracy \\
\hline Yaw & $\leq 0.18 \mathrm{mrad}$ (RMS) \\
Roll and pitch & $\leq 0.09 \mathrm{mrad}$ (RMS) \\
\hline
\end{tabular}

From Equation (6), the target guidance error caused by the GPS/INS unit can be obtained as shown in Equation (7), $\delta_{\text {azimuth }}=0.18 \mathrm{mrad}(\mathrm{RMS})$ and $\delta_{\text {elevation }}=0.09 \mathrm{mrad}(\mathrm{RMS})$.

$$
\delta_{\text {guidance }}=\sqrt{\delta_{\text {azimuth }^{2}+\delta_{\text {elevation }}^{2}}}=0.202 \mathrm{mrad}
$$

To improve the precision of the attitude compensation, the ship's attitude at the present moment as measured by the GPS/INS unit is used to predict the ship's attitude at a future time, while the guidance value of the target is pre-compensated. We used attitude velocity filtering and extrapolation to compensate the attitude lag. The running cycle of the software is $20 \mathrm{~ms}$, and the attitude measurement data sent to the controller for execution needs three frames, a total of $60 \mathrm{~ms}$. Areal-time lag compensation of $60 \mathrm{~ms}$ was determined by testing the lag frame number on the swing table, so that the precision of the line-of-sight disturbance compensation reached the angular second level.

\subsection{Installation Error Model}

During the installation of the GPS/INS unit, inevitable installation errors are incurred between the measuring axis of the GPS/INS unit and the ATP pointing axis. If there is an error between the installation of the GPS/INS unit and the ATP, the attitude compensation accuracy will be affected and the pointing accuracy of the ATP will decrease. Therefore, after the installation of the GPS/INS unit and ATP, the rotation relationship between the platform coordinate system represented by the GPS/INS unit $\mathrm{O}-\mathrm{X}_{\mathrm{p}} \mathrm{Y}_{\mathrm{p}} \mathrm{Z}_{\mathrm{p}}$ and the shipborne ATP deck coordinate system $\mathrm{O}-\mathrm{X}_{\mathrm{c}} \mathrm{Y}_{\mathrm{c}} \mathrm{Z}_{\mathrm{c}}$ needs to be calibrated (Figure 4). When measuring the equipment attitude, it is necessary to convert the inertial attitude to the coordinate system of the equipment.

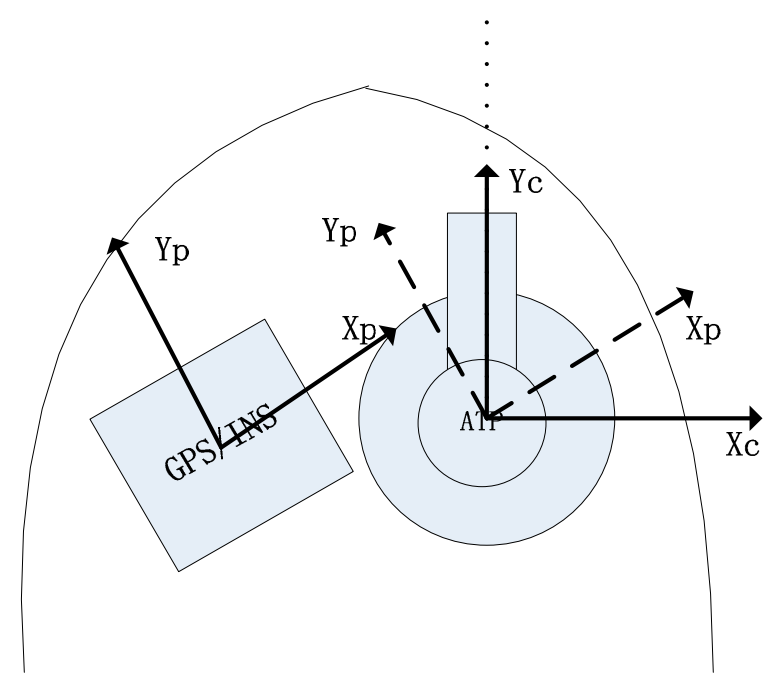

Figure 4. Error relation between the shipborne ATP and the GPS/INS unit.

The Equations (8) can be obtained from Equations (3) and (4), and Euler's theorem:

$$
\left[\begin{array}{l}
\mathrm{x}_{\mathrm{c}} \\
\mathrm{y}_{\mathrm{c}} \\
\mathrm{z}_{\mathrm{c}}
\end{array}\right]=\Psi t * \xi t *\left[\begin{array}{l}
\mathrm{x} \\
\mathrm{y} \\
\mathrm{z}
\end{array}\right]
$$


We can get from Equations (3) and (4), as shown in Equation (9).

$$
\left[\begin{array}{l}
L \cos \mathrm{E}_{\mathrm{c}} \cos \mathrm{A}_{\mathrm{c}} \\
L \cos \mathrm{E}_{\mathrm{c}} \sin \mathrm{A}_{\mathrm{c}} \\
L \sin \mathrm{E}_{\mathrm{c}}
\end{array}\right]=\Psi t * \xi t *\left[\begin{array}{c}
L \cos \mathrm{E} \cos \mathrm{A} \\
L \cos \mathrm{Esin} \mathrm{A} \\
L \sin \mathrm{E}
\end{array}\right]
$$

where $\left(A_{c^{\prime}}, E_{c}\right)$ represents the target polar coordinate in the deck coordinate system, $(A, E)$ represents the target coordinate value in the Northeast celestial coordinate system, $\xi t$ represents the attitude rotation matrix, and $\Psi t$ is the installation error matrix for the shipborne ATP and the GPS/INS unit.

$\Psi t$ is the parameter to be calibrated, $\Lambda_{c}$ and $\Lambda$ are coefficient matrices determined by experimental data, and the linear model of installation error can be expressed as Equation (10):

$$
\Lambda_{c}=\Psi t * \xi t * \Lambda+\Delta
$$

where, $\Lambda_{c}=\left[\begin{array}{l}L \cos \mathrm{E}_{\mathrm{c}} \cos \mathrm{A}_{\mathrm{c}} \\ L \cos \mathrm{E}_{\mathrm{c}} \sin \mathrm{A}_{\mathrm{c}} \\ L \sin \mathrm{E}_{\mathrm{c}}\end{array}\right], \Lambda=\left[\begin{array}{l}L \cos \mathrm{E} \cos \mathrm{A} \\ L \cos \mathrm{E} \sin \mathrm{A} \\ L \sin \mathrm{E}\end{array}\right], \Delta=[\alpha, \beta, \theta]^{T}$.

The method of "star tracker" is used to evaluate the absolute pointing error of telescope, which is the main method to determine the absolute pointing error of ATP [27]. Because of the high precision of the known positions of stars in the sky, the identification of star signals provides a powerful tool for checking the absolute ATP alignment. In practical application, a star is considered a measurable point in the sky, and the least square fitting technology provides a solution for the absolute pointing error assessment [28].

In fact, we know the theoretical coordinates of the stars $\left(\mathrm{A}_{\mathrm{i}}, \mathrm{E}_{\mathrm{i}}\right)$ in the Northeast celestial coordinate system. When measuring the star using the shipborne ATP, the measured value of the stars $\left(A_{c_{i}}, E_{c_{i}}\right)$ can be obtained from the deck coordinate system. Several stars in the all-sky region were measured, and the error matrix, $\hat{\Psi} t$ was obtained by fitting with the least square method.

To sum up, the undetermined parameter $\hat{\Psi} t$ of the installation error model is calibrated by the least square method, and the residual error $\Delta$ is calculated by substituting into Equation (10). We regard residual error $\Delta$ as the systematic error of ATP. In the next section, the residual error is further corrected by establishing the shipborne system error correction model to achieve a high absolute pointing accuracy.

\subsection{Systematic Errors Model}

Due to the influence of machining, installation, and other factors, the telescope contains systematic errors. The error sources include the non-verticality of the horizontal and vertical axes, non-orthogonality of the visual and horizontal axes, and bending of the mirror tube and displacement of the optical axis. For ground telescopes, the research on absolute pointing accuracy correction method is relatively mature $[29,30]$. But at present there is no good method to complete the high precision systematic error calibration on the mobile platform.

We take the installation error model and systematic error model into consideration, and get the following expression, as shown in Equation (11):

$$
\left\{\begin{array}{l}
\Delta \mathrm{A}_{\mathrm{c}_{\mathrm{i}}}=\hat{\mathrm{A}}_{\mathrm{c}_{\mathrm{i}}}-\mathrm{A}_{\mathrm{c}_{\mathrm{i}}}=f\left(\mathrm{~A}_{\mathrm{c}_{\mathrm{i}}}, \mathrm{E}_{\mathrm{c}_{\mathrm{i}}}\right)+\varepsilon_{i}, \mathrm{i}=1,2 \ldots, \mathrm{n} \\
\Delta \mathrm{E}_{\mathrm{c}_{\mathrm{i}}}=\hat{\mathrm{E}}_{\mathrm{C}_{\mathrm{i}}}-\mathrm{E}_{\mathrm{C}_{\mathrm{i}}}=g\left(\mathrm{~A}_{\mathrm{c}_{\mathrm{i}}}, \mathrm{E}_{\mathrm{C}_{\mathrm{i}}}\right)+\tau_{i}, \mathrm{i}=1,2 \ldots, \mathrm{n}
\end{array}\right.
$$

where, $\left(\hat{\mathrm{A}}_{\mathrm{c}_{\mathrm{i}}}, \hat{\mathrm{E}}_{\mathrm{C}_{\mathrm{i}}}\right)$ can be obtained from the equation $\hat{\Lambda}=\hat{\mathrm{\Psi}} t * \xi t * \Lambda,\left(\Delta \mathrm{A}_{\mathrm{c}_{\mathrm{i}}}, \Delta \mathrm{E}_{\mathrm{C}_{\mathrm{i}}}\right)$ are the observation error; $f\left(\mathrm{~A}_{\mathrm{c}_{\mathrm{i}}}, \mathrm{E}_{\mathrm{c}_{\mathrm{i}}}\right)$ and $g\left(\mathrm{~A}_{\mathrm{c}_{\mathrm{i}}}, \mathrm{E}_{\mathrm{c}_{\mathrm{i}}}\right)$ represent the approximate functions with the pointing angles $\left(\mathrm{A}_{\mathrm{c}_{\mathrm{i}}}, \mathrm{E}_{\mathrm{c}_{\mathrm{i}}}\right)$ as unknowns, that is, the systematic error correction model; $\varepsilon_{i}$ and $\tau_{i}$ are residual errors. 
According to Figure 2, the zero position of the azimuth encoder is no longer aligned with due North, but with the zero position of the fore-and-aft line. Therefore, we consider the deck coordinate system as the reference when designing the error model.

The expression for the mount model [31] is shown in Equation (12):

$$
\left\{\begin{array}{l}
\Delta \mathrm{A}_{\mathrm{c}_{\mathrm{i}}}=f\left(\mathrm{~A}_{\mathrm{c}_{\mathrm{i}},} \mathrm{E}_{\mathrm{c}_{\mathrm{i}}}\right)+\varepsilon_{i}=\sum_{j=1}^{m} \mathrm{~d}_{\mathrm{j}} \mathrm{Y}_{\mathrm{j}}\left(\mathrm{A}_{\mathrm{c}_{\mathrm{i}}}, \mathrm{E}_{\mathrm{c}_{\mathrm{i}}}\right)+\varepsilon_{i}, \mathrm{i}=1,2 \ldots, \mathrm{n} \\
\Delta \mathrm{E}_{\mathrm{c}_{\mathrm{i}}}=g\left(\mathrm{~A}_{\mathrm{c}_{\mathrm{i}}}, \mathrm{E}_{\mathrm{c}_{\mathrm{i}}}\right)+\tau_{i}=\sum_{j=1}^{m} \mathrm{~d}_{\mathrm{j}} \mathrm{\Gamma}_{\mathrm{j}}\left(\mathrm{A}_{\mathrm{c}_{\mathrm{i}}}, \mathrm{E}_{\mathrm{c}_{\mathrm{i}}}\right)+\tau_{i}, \mathrm{i}=1,2 \ldots, \mathrm{n}
\end{array}\right.
$$

where $d_{j}, j=1,2, \ldots, m$ are the model coefficients for the $m$ terms; $Y_{j}\left(A_{c_{i}}, E_{c_{i}}\right)$ represents the function in azimuth residual of the azimuth, $A_{c_{i}}$ and elevation $E_{c_{i}}$ of star $i, i=1,2, \ldots, n ; \Gamma_{j}\left(A_{c_{i}}, E_{c_{i}}\right)$ represents the function in elevation residual of the azimuth, $A_{c_{i}}$ and elevation $E_{c_{i}}$ of star $i, i=1,2, \ldots, n$. The ATP mount model is presented in Table 2.

Table 2. The ATP mount model.

\begin{tabular}{|c|c|c|c|}
\hline Term & Description & Azimuth Function (Y) & Elevation Function $(\Gamma)$ \\
\hline 1. & Azimuth encoder offset & 1 & - \\
\hline 2. & Elevation encoder offset & - & 1 \\
\hline 3. & $\begin{array}{l}\text { Azimuth axis tilt about } \\
\text { fore-and-aft line }\end{array}$ & $-\cos A_{c} \tan E_{c}$ & $\sin \mathrm{A}_{\mathrm{c}}$ \\
\hline $\begin{array}{l}4 . \\
5 .\end{array}$ & $\begin{array}{c}\text { Azimuth axis tilt about axis } Y_{c} \\
\text { optical axis misalign }\end{array}$ & $\begin{array}{l}-\sin A_{c} \tan E_{c} \\
\sec E_{c}\end{array}$ & $\begin{array}{c}-\cos A_{c} \\
-\end{array}$ \\
\hline 6. & $\begin{array}{l}\text { Non-orthogonality of Azimuth } \\
\text { and Elevation axes }\end{array}$ & $-\tan \mathrm{E}_{\mathrm{C}}$ & - \\
\hline 7. & Azimuth bearing ellipticity (sin) & $\sin A_{c}$ & - \\
\hline 8. & Azimuth bearing ellipticity (cos) & $\cos A_{c}$ & - \\
\hline 9. & Azimuth bearing ellipticity (sin) & - & $\sin E_{c}$ \\
\hline 10. & Azimuth bearing ellipticity (cos) & - & $\cos \mathrm{E}_{\mathrm{c}}$ \\
\hline 11. & Telescope tube flexure & - & $\cot E_{c}$ \\
\hline 12. & Azimuth encoder scale error & $\mathrm{A}_{\mathrm{c}} / 2 \pi$ & - \\
\hline 13. & Elevation encoder scale error & - & $\mathrm{E}_{\mathrm{c}} / 2 \pi$ \\
\hline 14. & Bi-periodic in azimuth & $\cos 2 \mathrm{~A}_{\mathrm{C}}$ & - \\
\hline 15. & Elevation encoder stiction & - & $\sin A_{c}$ \\
\hline 16. & Elevation bearing stiction & - & $E_{C} \sin A_{c}$ \\
\hline
\end{tabular}

\subsection{Installation and Systematic Error Model Calculation and Application Process}

The installation and systematic error model can be obtained by the shipborne ATP's software automatically as shown in Figure 5a. ATP tracks and measures about 20 stars (magnitude less than 6, etc.) uniformly throughout the sky. Then the star's theoretical position $\left(A_{i}, E_{i}\right)$, measurement position $\left(\mathrm{A}_{\mathrm{c}_{\mathrm{i}}}, \mathrm{E}_{\mathrm{C}_{\mathrm{i}}}\right)$, and ship attitude $\left(\mathrm{H}_{\mathrm{i}}, \mathrm{P}_{\mathrm{i}}, \mathrm{R}_{\mathrm{i}}\right)$ can be recorded. Once the measurements are available, the telescope will automatically track and measure the next star. The installation error matrix and systematic error model are solved by the least square method after all the stars measurement data are obtained. The whole process takes less than $10 \mathrm{~min}$.

In the acquisition mode, the ideal point angle (A, E) in the Northeast celestial coordinate system is calculated according to the relationship between the target guidance position and the position of the ship. According to the measured attitude $(\mathrm{H}, \mathrm{P}, \mathrm{R})$ and the installation error matrix $\Psi t$, the guidance value $\left(A_{c}, E_{c}\right)$ in the deck coordinate system can be calculated. Then, according to the pointing error correction model, the pointing error $\left(\Delta \mathrm{A}_{\mathrm{c}}, \Delta \mathrm{E}_{\mathrm{c}}\right)$ corresponding to the $\left(\mathrm{A}_{\mathrm{c}}, \mathrm{E}_{\mathrm{c}}\right)$ pointing angle is solved. Finally, the pointing error $\left(\Delta \mathrm{A}_{c}, \Delta \mathrm{E}_{\mathrm{c}}\right)$ is used to correct the actual pointing angle $\left(\mathrm{A}_{\mathrm{c}}, \mathrm{E}_{\mathrm{c}}\right)$, and the correct pointing angle $\left(\hat{\mathrm{A}}_{\mathrm{c}}, \hat{\mathrm{E}}_{\mathrm{c}}\right)$ is obtained as shown in Figure $5 \mathrm{~b}$. 


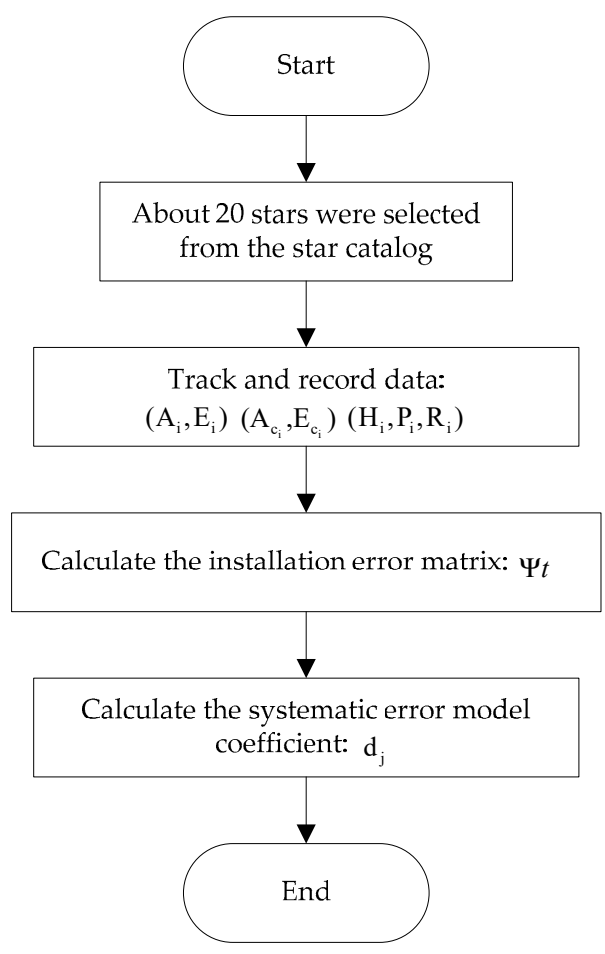

(a)

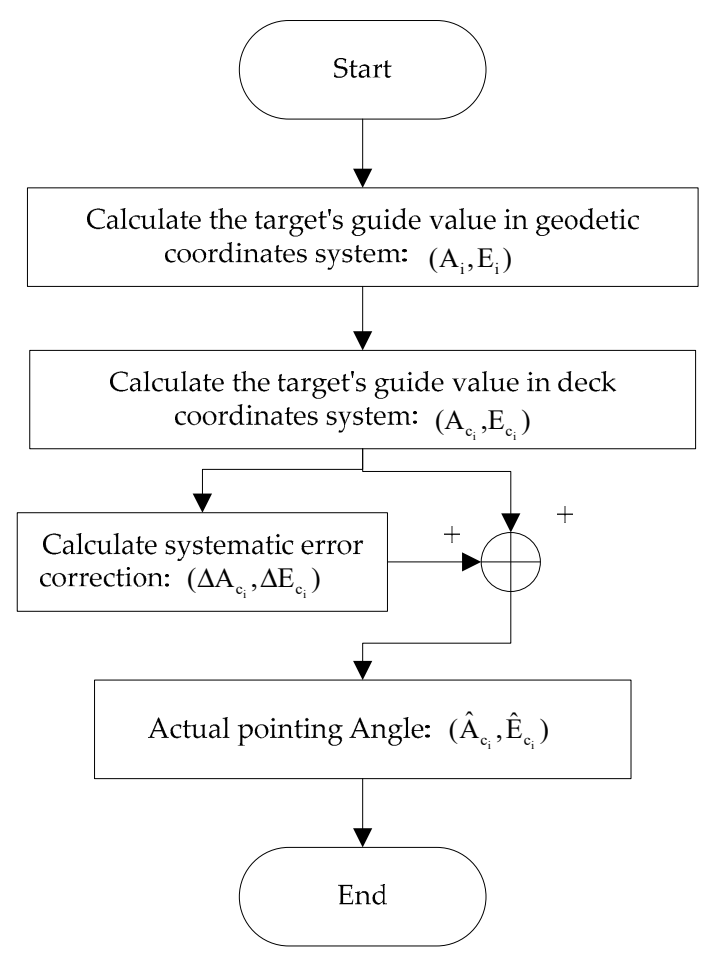

(b)

Figure 5. Installation and systematic error model calculation and application process. (a) Installation and system error model calculation flow chart. (b) Flow chart of actual use.

\section{Experiment and Results}

We developed a shipborne ATP system (Figure 6) mainly to verify the ability for acquisition and pointing, hence, a fast-steering mirror was not used at the fine pointing stage. The primary mirror in the ATP system is a reflecting Cassegrain telescope with an aperture of $75 \mathrm{~mm}$ and a focal length of $200 \mathrm{~mm}$. The coarse-control loop included a two-axis gimbal telescope (azimuth rotation range of about $-360^{\circ}$ to $+360^{\circ}$, elevation rotation range of about $-5^{\circ}$ to $+90^{\circ}$ ) and a CCD camera (FOV of $0.97^{\circ} \times 0.91^{\circ}$, frame rate of $50 \mathrm{~Hz}$ ).

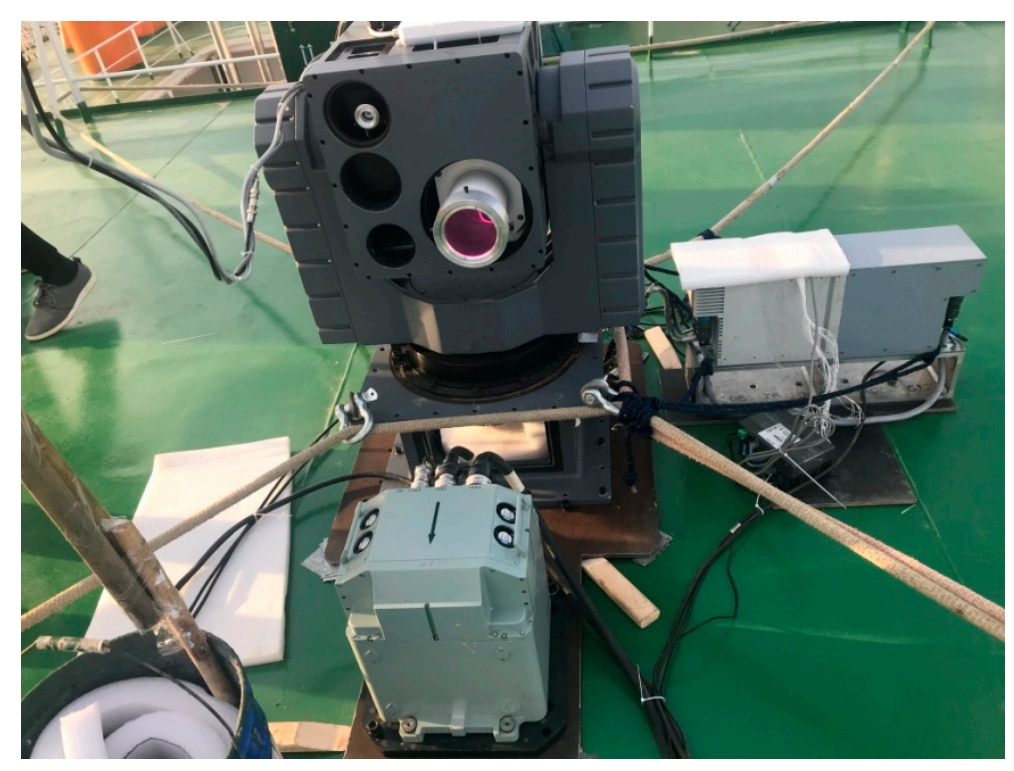

Figure 6. The shipborne ATP system. The shipborne ATP system shows the uplink beacon, coarse camera, and the attitude pre-compensation unit. 
We set up the ATP system terminal on an experimental ship at Dalian city. After the installation of the ATP system, the experimental ship sailed to an experimental site $\left(38^{\circ} 48.027^{\prime} \mathrm{N}, 121^{\circ} 50.037^{\prime} \mathrm{E}\right)$ in the sea. We calibrated the ATP system's pointing ability by tracking and measuring a batch of stars one hour before the experiment. The residual error after installation error correction is shown in Figure 7 while the residual error after systematic error correction is shown in Figure 8. After obtaining the ATP system error model, a batch of stars were tracked and measured to verify the accuracy of the system error model. We used the shipborne ATP to track 15 stars with open-loop and obtained the pointing accuracy. The absolute pointing error obtained for the shipborne ATP azimuth was117.8 $\mu \mathrm{rad}$ whereas the elevation was $128.1 \mu$ rad (Figure 9). The total pointing error of ATP is given by $\delta_{\text {pointing error, }}$ as shown Equation (13).

$$
\delta_{\text {pointing error }}=\sqrt{\delta_{\text {azimuth }^{2}+\delta_{\text {elevation }}^{2}}}=0.174 \mathrm{mrad}
$$
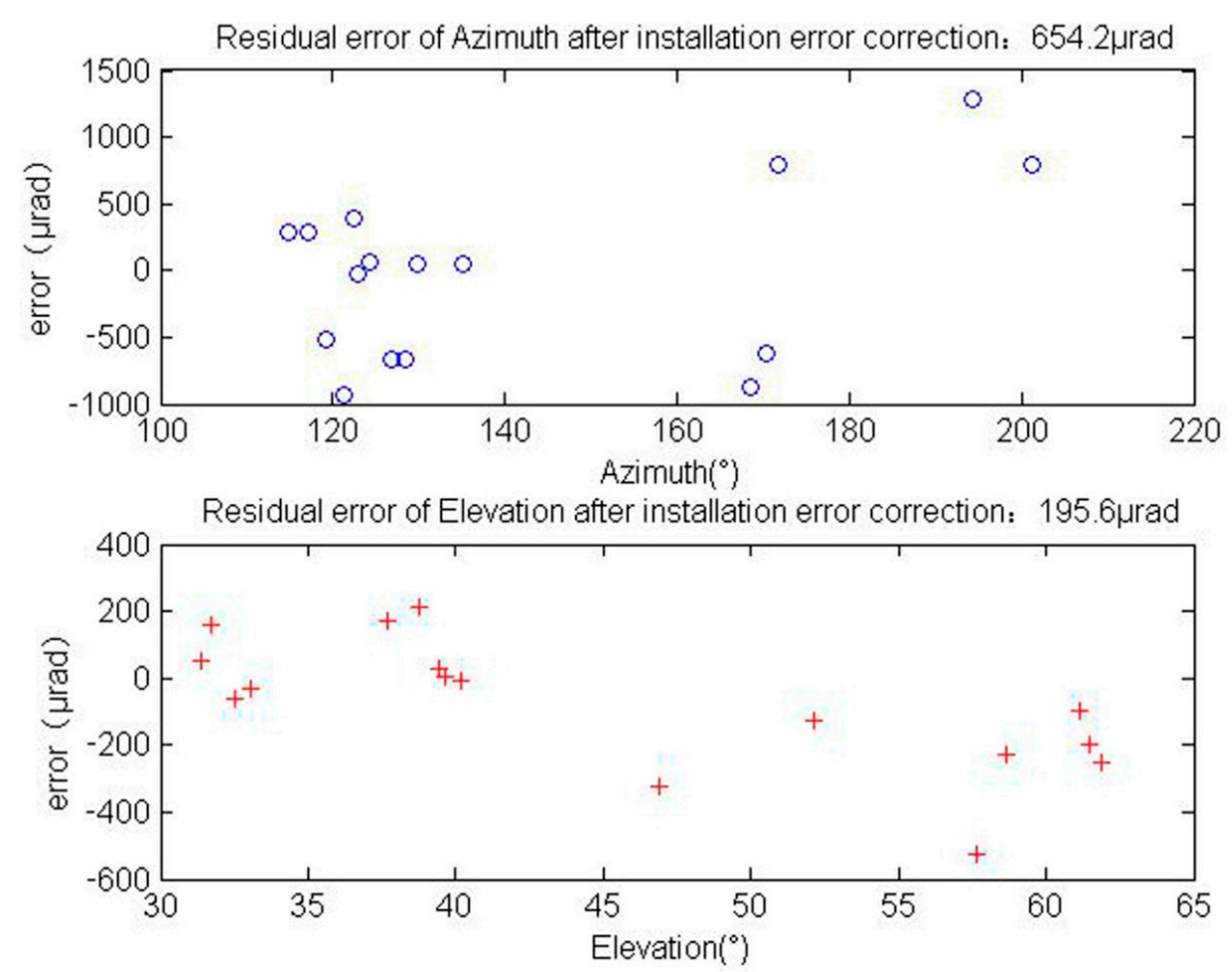

Figure 7. Residual error after installation error calibration. The azimuth residual error is $654.2 \mu \mathrm{rad}$ while the elevation residual error is $195.6 \mu \mathrm{rad}$. 

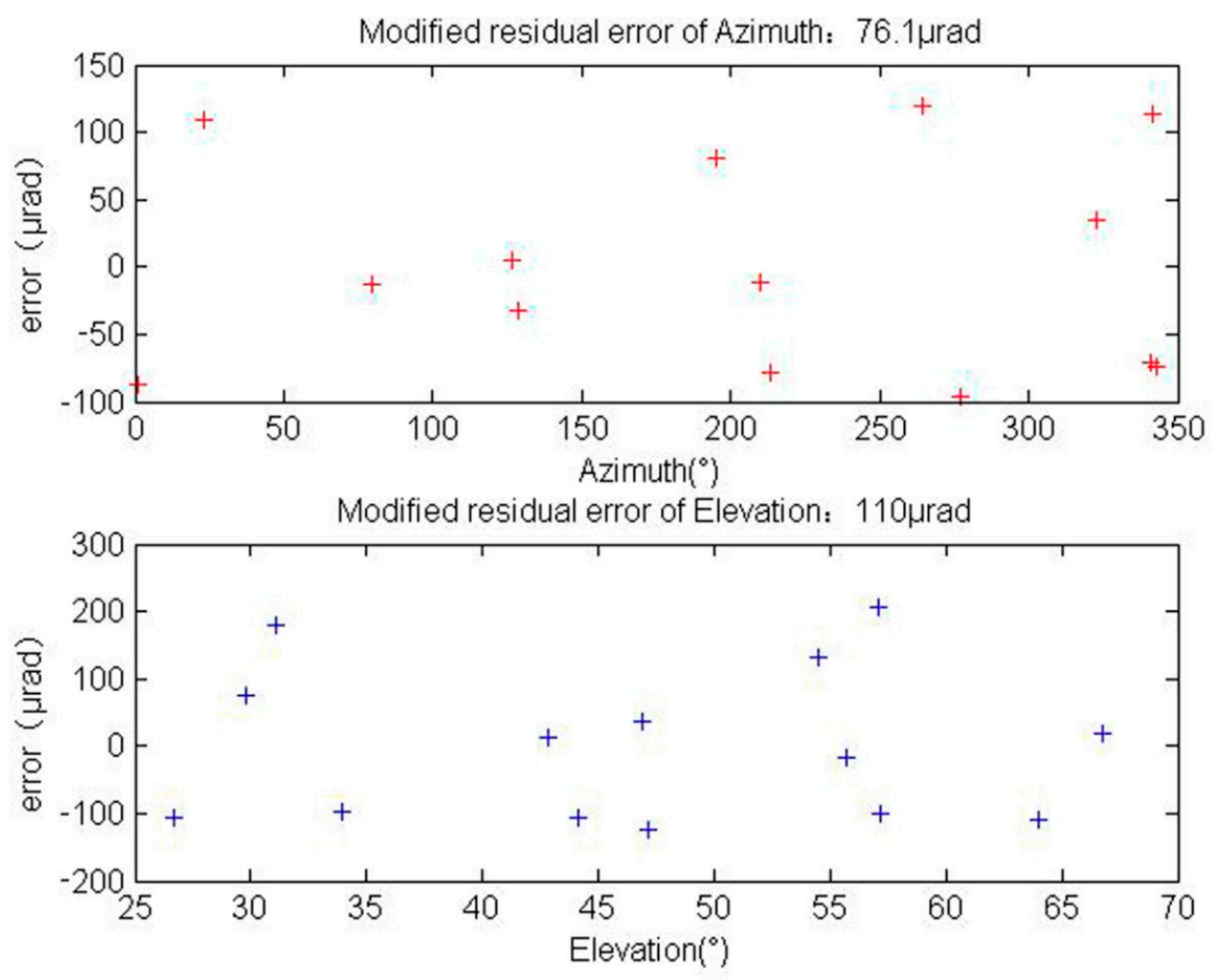

Figure 8. Residual error after systematic error correction. The azimuth residual error was obtained as $76.1 \mu \mathrm{rad}$ while the elevation residual error was110 $\mu \mathrm{rad}$.

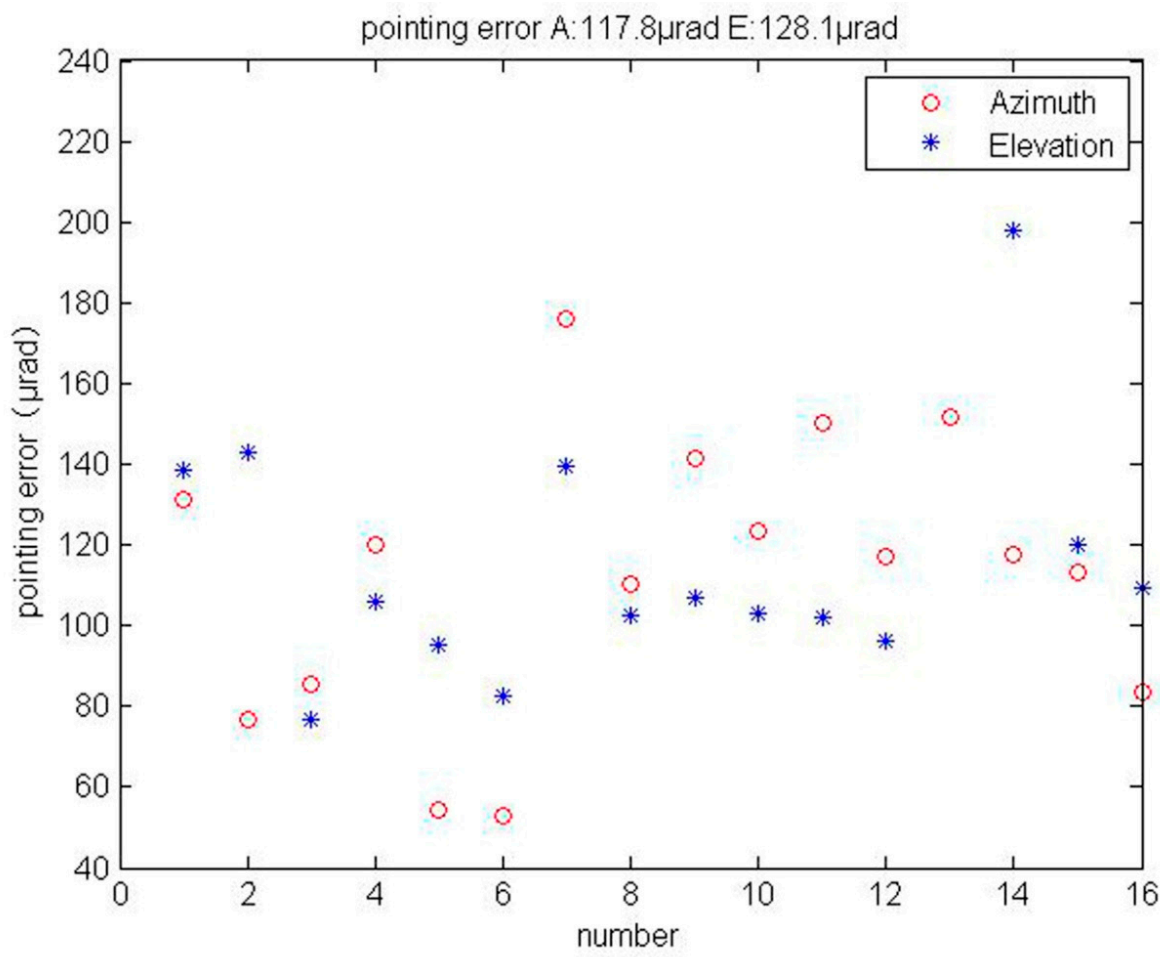

Figure 9. Pointing error of azimuth and elevation. Azimuth pointing error is $117.8 \mu \mathrm{rad}$ and elevation pointing error is $128.1 \mu \mathrm{rad}$.

Figure 10 shows the performance of the shipborne ATP with respect to the acquisition and tracking of a satellite. The azimuth and elevation tracking errors were both less than $20 \mu \mathrm{rad}$ (RMS). The azimuth 
initial acquisition error was $310 \mu \mathrm{rad}$ whereas the elevation initial acquisition error was $160 \mu \mathrm{rad}$. This error includes the orbital error of the satellite.

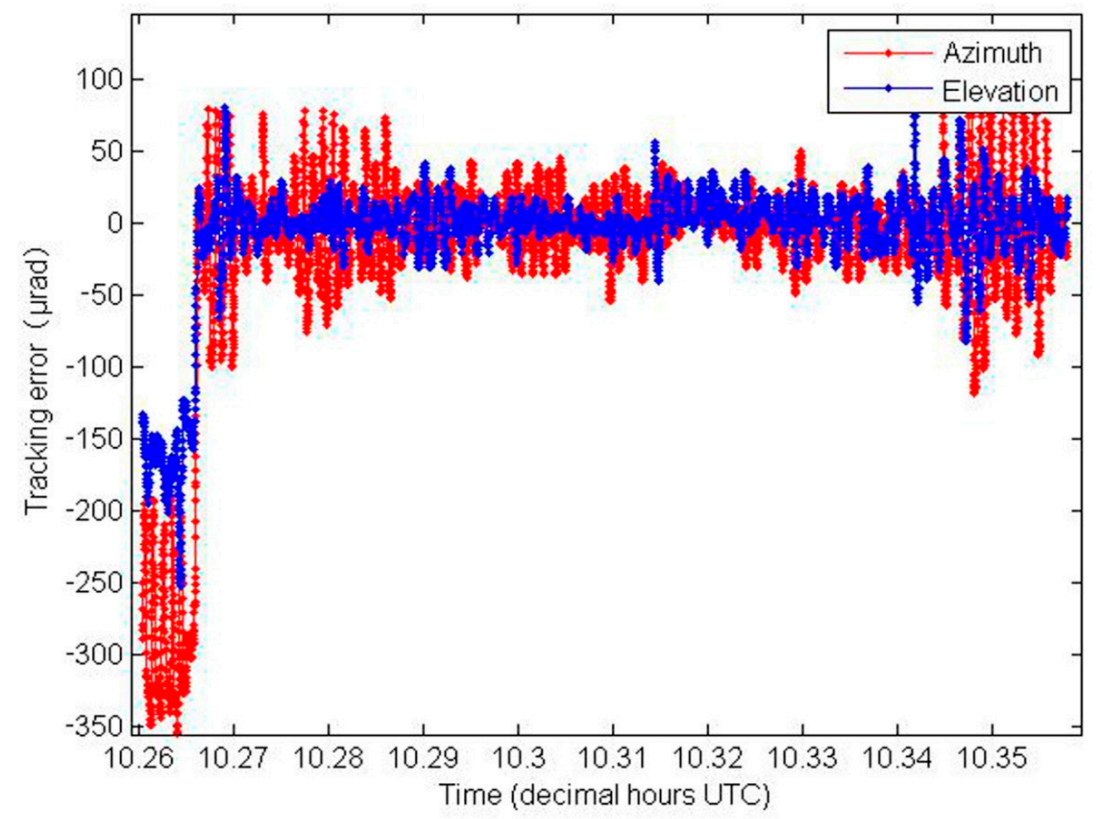

(a)
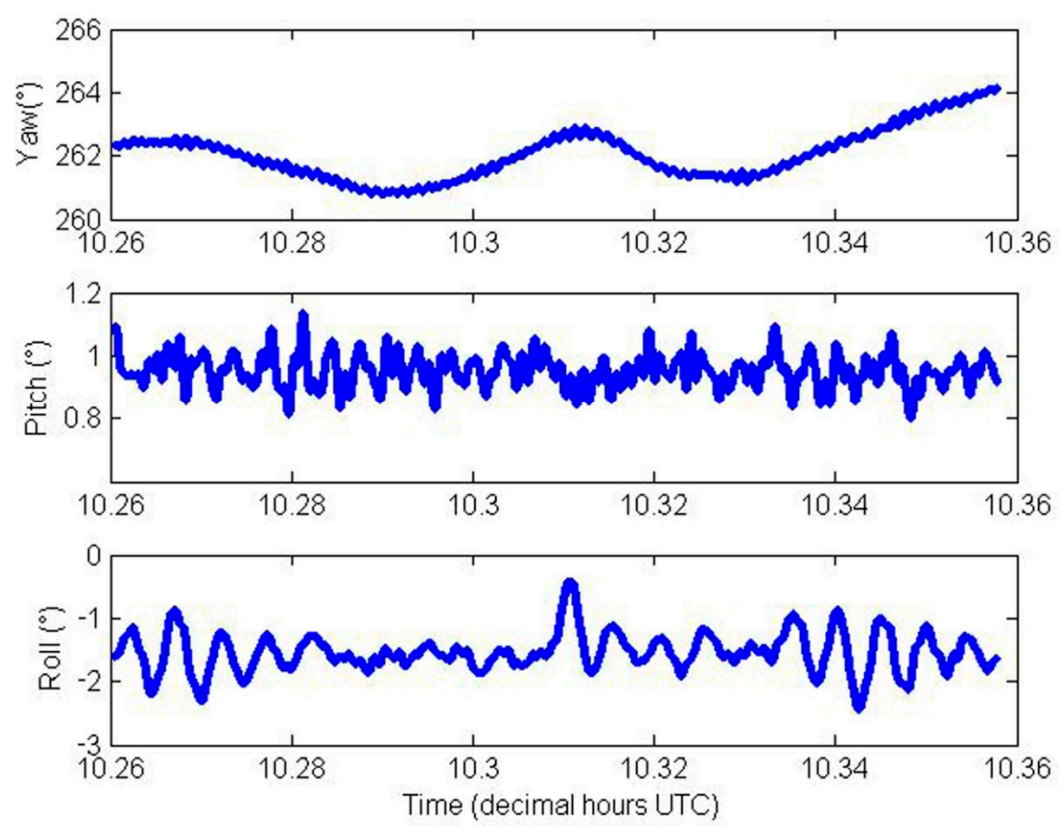

(b)

Figure 10. The shipborne ATP acquired and tracked the performance of a satellite. (a) The tracking error for the entire process and the initial error just appear in the field of view. The azimuth initial acquisition error was $310 \mu \mathrm{rad}$ whereas the elevation initial acquisition error was $160 \mu \mathrm{rad}$. When the spot was in the tracking field, the azimuth tracking error was about $19.5 \mu \mathrm{rad}$ (RMS) while the elevation tracking error was about 14.6 $\mu$ rad (RMS). The tracking error in the stabilized time lasted from 10:15:58 to 10:21:28, about 330 seconds. (b) Ship attitude measurement. The yaw, pitch, and roll curves of the ship measured by the GPS/INS unit. 


\section{Conclusions}

We tracked some stars at sea, achieving a pointing accuracy of less than $180 \mu \mathrm{rad}$. We acquired and tracked some Low-Earth-orbit satellites at sea, achieving a tracking accuracy of about $20 \mu \mathrm{rad}$. In this work, we have taken other sources of error into account, including position and alignment errors. The initial coarse orientation of the ATP was based on the satellite's predicted orbital position, with an uncertainty generally less than $200 \mathrm{~m}$.A position error is less than $0.1 \mathrm{mrad}$ at $2000 \mathrm{~km}$. An alignment error of less than 0.05 mradcan be achieved between the beacon laser and tracking camera after adjustment. We can obtain a total initial open-loop pointing error of less than $0.324 \mathrm{mrad}$, including position error (less than $0.1 \mathrm{mrad}$ at $2000 \mathrm{~km}$ ), pointing error (less than $0.174 \mathrm{mrad}$ ), and alignment error between the beacon laser and tracking camera (less than $0.05 \mathrm{mrad}$ ). In accordance with two-dimensional Gaussian distributions, if the acquisition probability reaches $98.9 \%$, the initial open-loop pointing error (RMS) of the shipborne ATP must be less than one-sixth of the beacon divergence angle. If the divergence angle of the ATP uplink beacon laser is greater than $2 \mathrm{mrad}$, the shipborne ATP system open-loop pointing beacon laser spot can irradiate the satellite. Therefore, by verifying the pointing accuracy of the shipborne ATP and selecting the appropriate divergence angle for the uplink beacon, optical links between the shipborne ATP and the satellite can be established. We achieved significant experimental results for the shipborne ATP acquisition and tracking that will contribute to the realization of laser communication in free space between satellites and the sea.

Author Contributions: Conceptualization, D.H. and Y.H.; funding acquisition, Y.T., G.R., B.Q. and Y.H.; investigation, Q.W. and Z.S.; methodology, D.H., Q.W., Z.S., J.R. and Y.C.; project administration, Y.T.; resources, X.L., Z.S., J.Z., Z.W., T.Z., J.R. and Y.C.; software, D.H., Q.W., X.L., C.G., T.Z. and X.Q.; supervision, G.R., B.Q. and Y.H.; validation, X.L., J.Z. and C.G.; visualization, Z.W. and X.Q.; writing-original draft, D.H.; writing-review \& editing, D.H.

Funding: This research was funded by the Natural National Science Foundation of China (NSFC), grant number (U1738204).

Acknowledgments: Thanks to our colleagues in the Key Laboratory of Optical Engineering, Chinese Academy of Sciences. Thanks for the financial support from Youth Innovation Promotion Association, Chinese Academy of Sciences.

Conflicts of Interest: The authors declare no conflict of interest.

\section{References}

1. Chan, V.W.S. Free-space optical communications. J. Light. Technol. 2007, 24, 4750-4762. [CrossRef]

2. Das, S.; Henniger, H.; Epple, B.; Moore, C.I.; Rabinovich, W.; Sova, R.; Young, D. Requirements and challenges for tactical free-space Lasercomm. In Proceedings of the MILCOM 2008-2008 IEEE Military Communications Conference, San Diego, CA, USA, 16-19 November 2008; IEEE: Piscataway, NJ, USA, 2009.

3. Kim, I.I. Wireless optical transmission of fast ethernet, FDDI, ATM, and ESCON protocol data using the Terra Link laser communication system. Opt. Eng. 1998, 37, 3143. [CrossRef]

4. Kim, I.I. Comparison of laser beam propagation at $785 \mathrm{~nm}$ and $1550 \mathrm{~nm}$ in fog and haze for optical wireless communications. Proc. SPIE 2001, 4214, 26-37.

5. Maynard, J.A.; Begley, D. Airborne laser communications: Past, present and future. Proc. SPIE Int. Soc. Opt. Eng. 2005, 5892. [CrossRef]

6. Fletcher, T.M.; Cunningham, J.; Baber, D.; Wickholm, D.; Goode, T.; Gaughan, B.; Burgan, S.; Deck, A.; Young, D.W.; Juarez, J.; et al. Observations of atmospheric effects for FALCON laser communication system flight test. Proc. SPIE 2011, 8038, 80380F-1-80380F-12.

7. Moll, F.; Horwath, J.; Shrestha, A.; Brechtelsbauer, M.; Fuchs, C.; Navajas, L.A.M.; Souto, A.M.L.; González, D.D. Demonstration of high-rate laser communications from a fast airborne platform. IEEE J. Sel. Areas Commun. 2015, 33, 1985-1995. [CrossRef]

8. Guelman, M.; Kogan, A.; Kazarian, A.; Livne, A.; Orenstein, M.; Michalik, H. Acquisition and pointing control for inter-satellite laser communications. IEEE Trans. Aerosp. Electron. Syst. 2004, 40, 1239-1248. [CrossRef] 
9. Sodnik, Z.; Furch, B.; Lutz, H. Optical inter satellite communication. IEEE J. Sel. Top. Quantum Electron. 2010, 16, 1051-1057. [CrossRef]

10. Toyoshima, M.; Takayama, Y.; Takahashi, T.; Suzuki, K.; Kimura, S.; Takizawa, K.; Kuri, T.; Klaus, W.; Toyoda, M.; Kunimori, H.; et al. Ground-to-satellite laser communication experiments. IEEE Aerosp. Electron. Syst. Mag. 2008, 23, 10-18. [CrossRef]

11. Boroson, D.M.; Robinson, B.S. The lunar laser communication demonstration: NASA's first step toward very high data rate support of science and exploration missions. Space Sci. Rev. 2014, 185, 115-128. [CrossRef]

12. Robinson, B.S.; Boroson, D.M.; Burianek, D.A.; Murphy, D.V. The lunar laser communications demonstration. In Proceedings of the 2011 International Conference on Space Optical Systems and Applications (ICSOS), Santa Monica, CA, USA, 11-13 May 2011; IEEE: Piscataway, NJ, USA, 2011.

13. Wang, J.; Lv, J.; Zhao, G.; Wang, G. Free-space laser communication system with rapid acquisition based on astronomical telescopes. Opt. Express 2015, 23, 20655-20667. [CrossRef] [PubMed]

14. Wuchenich, D.M.R.; Mahrdt, C.; Sheard, B.S.; Francis, S.P.; Spero, R.E.; Miller, J.; Mow-Lowry, C.M.; Ward, R.L.; Klipstein, W.M.; Heinzel, G.; et al. Laser link acquisition demonstration for the GRACE Follow-On mission. Opt. Express 2014, 22, 11351-11366. [CrossRef] [PubMed]

15. Yin, J.; Cao, Y.; Li, Y.H.; Liao, S.; Zhang, L.; Ren, J.; Cai, W.; Liu, W.; Li, B.; Dai, H.; et al. Satellite-based entanglement distribution over 1200 kilometers. Science 2017, 356, 1140-1144. [CrossRef] [PubMed]

16. Liao, S.K.; Cai, W.Q.; Liu, W.Y.; Zhang, L.; Li, Y.; Ren, J.; Yin, J.; Shen, Q.; Cao, Y.; Li, Z.; et al. Satellite-to-ground quantum key distribution. Nature 2017, 549, 43-47. [CrossRef] [PubMed]

17. Rabinovich, W.S.; Moore, C.I.; Mahon, R.; Goetz, P.G.; Burris, H.R.; Ferraro, M.S.; Murphy, J.L.; Thomas, L.M.; Gilbreath, G.C.; Vilcheck, M.; et al. Free-space optical communications research and demonstrations at the US Naval Research Laboratory. Appl. Opt. 2015, 54, F189-F200. [CrossRef] [PubMed]

18. Gilbreath, G.C.; Rabinovich, W.S.; Moore, C.I.; Burris, H.R.; Mahon, R.; Grant, K.J.; Goetz, P.G.; Murphy, J.L.; Voelz, D.G.; Ricklin, J.C.; et al. Progress in laser propagation in a maritime environment at the Naval Research Laboratory. In Proceedings of the Free-Space Laser Communications V, SPIE Optics \& Photonics 2005, San Diego, CA, USA, 31 July 2005; SPIE: Bellingham, WA, USA, 2005; Volume 5892, pp. 605-613.

19. Wu, R.; Zhao, X.; Liu, Y.; Song, Y. Initial pointing technology of line of sight and its experimental testing in dynamic laser communication system. IEEE Photonics J. 2019, 11, 1-8. [CrossRef]

20. Zhao, X.; Liu, Y.Q.; Song, Y. Line of sight pointing technology for laser communication system between aircrafts. Opt. Eng. 2017, 56, 126107. [CrossRef]

21. Klein, M.B.; Sipman, R.H. Large aperture Stark modulated retroreflector at 10.8 microns. J. Appl. Phys. 1980, 51, 6101-6104. [CrossRef]

22. Rabinovich, W.S.; Mahon, R.; Gilbreath, G.C.; Burris, R.; Goetz, P.G.; Moore, C.I.; Ferraro-Stell, M.; Witkowsky, J.L.; Swingen, L.; Oh, E.; et al. Free-space optical communication link at $1550 \mathrm{~nm}$ using multiple quantum well modulating retro-reflectors over a 1-kilometer range. In Proceedings of the Conference on Lasers and Electro-Optics, 2003, CLEO '03, Baltimore, MD, USA, 6 June 2003; IEEE: Piscataway, NJ, USA, 2004.

23. Rabinovich, W.S.; Goetz, P.G.; Mahon, R.; Swingen, L.A.; Murphy, J.L.; Ferraro, M.; Burris, H.R.; Moore, C.I.; Suite, M.R.; Gilbreath, G.C.; et al. 45-Mbit/s cat's-eye modulating retroreflectors. Opt. Eng. 2007, 46, 104001. [CrossRef]

24. Peter, G.G.; Mahon, R.; James, L.M.; Mike, S.F.; Michele, R.S.; Walter, R.S.; Ben, B.X.; Harris, R.B.; Christopher, I.M.; William, S.R.; et al. Modulating retro-reflector lasercom systems at the Naval Research Laboratory. In Proceedings of the Military Communications Conference, 2010-MILCOM, San Jose, CA, USA, 31 October-3 November 2010; IEEE: Piscataway, NJ, USA, 2010.

25. Majumdar, A.K. Modulating retroreflector-based free-space optical (FSO) communications. In Advanced Free Space Optics (FSO); Springer: New York, NY, USA, 2015.

26. Mutilba, U.; Kortaberria, G.; Egaña, F.; Yagüe-Fabra, J.A. 3D Measurement Simulation and Relative Pointing Error Verification of the Telescope Mount Assembly Subsystem for the Large Synoptic Survey Telescope. Sensors 2018, 18, 3023. [CrossRef]

27. Huang, L.; Ma, W.; Huang, J. Modeling and calibration of pointing errors with alt-az telescope. New Astron. 2016, 47, 105-110. [CrossRef]

28. Tiziani, D.; Garczarczyk, M.; Oakes, L.; Schwanke, U.; van Eldik, C. A Pointing Solution for the Medium Size Telescopes for the Cherenkov Telescope Array. AIP Conf. Proc. 2017. [CrossRef] 
29. Cheng, J. The Principles of Astronomical Telescope Design; Springer: New York, NY, USA, 2009.

30. Donato, C.D.; Prouza, M.; Sanchez, F.; Santander, M.; Camin, D.; Garcia, B.; Grassi, V.; Grygar, J.; Hrabovský, M.; Řídký, J.; et al. Using stars to determine the absolute pointing of the fluorescence detector telescopes of the Pierre Auger Observatory. Astropart. Phys. 2007, 28, 216-231. [CrossRef]

31. Luck, J. Mount Model Stability. In Proceedings of the 14th International Workshop on Laser Ranging Instrumentation, San Fernando, Spain, 7-11 June 2004.

(c)

(C) 2019 by the authors. Licensee MDPI, Basel, Switzerland. This article is an open access article distributed under the terms and conditions of the Creative Commons Attribution (CC BY) license (http://creativecommons.org/licenses/by/4.0/). 